Animal Production in Developing Countries

Occasional Publication No. 16 - British Society of Animal Production 1993

edited by M. Gill, E. Owen, G. E. Pollott and T. L. J. Lawrence

\title{
Smallholder goat production in Malawi
}

\author{
H. P. Zerfas, M. Klein and C. von Morstein \\ GTZ - Malazvi-German Livestock Development Programme, Box 30549, Lilongwe 3, Malawi \\ JLU - Division of Livestock Ecology, Tropical Sciences Centre, Ludwigstrasse 21, D-6300 Giessen, Germany
}

\section{Introduction}

Goat husbandry is a vital enterprise for smallholder farmers in Malawi (meat supply, social security etc.). The present system is determined by high outputinput ratios. Local goats are highly productive but crossbreeding with Boer goats seems to enhance the output significantly. The net off-take per doe and year of $15.0 \mathrm{~kg}$ can be increased through improvements in animal health, housing, feeding, breeding and marketing. The results and conclusions of a long-term survey are being implemented into an extension package for farmers, field assistants, veterinary assistants and agricultural officers of all levels.

\section{Material and methods}

A survey comprising $\mathbf{5 0}$ smallholder farmers keeping a total of 1000 goats was launched in 1984. All animals were ear tagged for identification. Flock increases (births, purchases, transfers, exchanges) and decreases (deaths, sales, slaughters, losses, predations, transfers, exchanges) were recorded fortnightly. All animals were weighed quarterly and a sample of $\mathbf{3 0 0}$ animals, monthly. Crossbreeding of local goats with Boer goats of different grades was introduced on a trial basis.

Further information was gained by a farming systems survey conducted in 1987/1988.

\section{Results}

All genotypes showed an aseasonal breeding behaviour.

Ages at first kidding (least-square mean) of local, $1 / 2$ Boer and $3 / 8$ Boer goats of 470 (s.e. 6), 489 (s.e. 11) and 458 (s.e. 12) days respectively were not statistically different.

The kidding intervals (least-square means) of 263 (s.e. 2), 280 (s.e. 7) and 258 (s.e. 9) days for locals, 1/2 Boers and 3/8 Boers respectively were not significantly different. The abortion rate of pregnant goats was $5 \cdot 5 \%$.

Least-square mean litter size at birth did not differ between local (1.68 (s.e. 0.02)) and $1 / 2$ Boer goats
(1.63 (s.e. 0.02)) but was significantly higher $(P<0.01)$ in $3 / 8$ Boer goats $(1.73$ (s.e. 0.03)) compared with local goats. The birth-month affected litter size significantly $(P<0.01)$.

The least-square mean mortality rates of kids in the 1st year of 42 (s.e. 2)\%, 31 (s.e. 3 ) \% and 28 (s.e. 4 )\% in local, 1/2 Boer and 3/8 Boer goats respectively was significantly higher in locals $(P<0.001)$. The majority of deaths were in the rainy season.

Weights at 1 year of age (least-square mean) proved to be significantly $(P<0.001)$ lower in local goats (20.1 (s.e. 0.9) kg) compared with $1 / 2$ Boers $(22.9$ (s.e. $0.9) \mathrm{kg}$ ) and $3 / 8$ Boers ( 24.9 (s.e. 1.5$) \mathrm{kg}$ ). Seasonal (rainy - dry) effects on the weight development were not significant, at any age.

Goat production contributed proportionately 0.19 (range : 0 to 0.55 ) to the on-farm income of the survey farmers.

\section{Further observations}

Crossbreeding the local with the Boer goat can increase the productivity significantly, but the effects of up-grading have to be assessed thoroughly.

Herding of goats in the rainy season increases the weight gains compared with tethering.

Frequent changes of the grazing area results in a lower worm burden and lower mortality rate.

Proper thatching of stables improves the kid survival rate.

Established goat markets increase the cash income of smallholder farmers.

Fodder shrubs such as Leucaena leucocephala have to be protected from goats until sufficiently matured to withstand browsing.

\section{Acknowledgements}

The authors acknowledge support from GTZ and the Department of Animal Health and Industries (DAHI), Malawi. 